\title{
A SOCIOTERRITORIALIDADE DA AMAZÔNIA E AS POLÍTICASDE EDUCAÇÃO DO CAMPO
}

\author{
Lơena Maria MarãodeOlivera* \\ SalomãoAntanioMufarré Hagé
}

Resumo: 0 artigo analisa a relação entre diversidade socioterritorial, políticas públicas e E ducação do Campo, no contexto da diversidade socioterritorial da Amazônia Paraense. Ele foi elaborado por meio de um estudo bibliográfico e documental que concebe o território numa perspectiva relacional e complexa, como espaço formado por múltiplas dimensões: econômica, política, cultural e ecológica. Apresenta una cartografia da diversidade socioterritorial do campo, na A mazônia Paraense, explicitando as ter ritorialidades dos rios, das colônias rurais, dos assentamentos, das reservas extrativistas, dos quilombos edas áreas indígenas, esuas implicações para políticas públicas de E ducação do Campo na A mazônia Paraense.

Palavras-chave: Território. Amazônia. Diversidade. Políticas educacionais. E ducação do Campo.

\section{THE SOCIO-TERRITORIALITY OF THE AMAZON, AND THE POLICIES FOR RURAL EDUCATION}

Abstract: This article analyzes the relationship between territory, public policies and rural education within the context of the socio-territorial diversity of the A mazonian region in the state of Pará. The analysis emphasizes the centrality of the social movements' protagonism in the region, as well as in the larger Brazilian context, the rationale being an understanding of territory that privileges relationality and complexity with respect to economic, political, cultural and ecological dimensions. Lastly, the socio-territorial diversity within the A mazonian region of Pará state is mapped, highlighting the territoriality of rivers, rural colonies, settlements, extractive reserves, 'quilombos', and indigenous reservations.

Keywords: Territory. A mazon. D iversity. E ducational policies. Rural education.

\footnotetext{
* M estre em E ducação (U niversidade Federal do Pará). Professora da Secretaria E stadual de E ducação (SE D U C). Professo ra da Faculdade do Pará (FAP).

${ }^{*}$ D outor em E ducação (Pontifícia U niversidade Católica de São Paulo). Professor da U niversidade Federal do Pará - UFPA (Programa de Pós-G raduação em Linguagens e Saberes da Amazônia; Programa de Pós-G raduação em E ducação; Faculdade de Pedagogia).
} 


\section{INTRODUÇÃO}

E sse artigo tem origem e fundamentação em uma dissertação de mestrado produzida no Programa de Pós-G raduação em E ducação, da Universidade Federal do Pará, no ano de 2010. E sse trabalho dissertativo utilizou-se de revisão bibliográfica e pesquisa documental para analisar as políticas curriculares da Secretaria de E stado de E ducação do Pará (SE D U C/ PA) que possuem relação com a E ducação do Campo. A dotou-se em tal investigação a abordagem territorial, cujo lócus de referência é a A mazônia Paraense.

No cenário nacional mais recente, a abordagem territorial encontra-se em evidência, devido ao reconhecimento da importância de se levar em conta as diversidades socioterritoriais na configuração de políticas públicas voltadas para o desenvolvimento do país, reconhecimento esse provocado, em grande medida, pelo protagonismo e reivindicação dos movimentos sociais.

As diretrizes educacionais atuais do governo federal direcionadas, especificamente, à Educação do Campo, são exemplos da utilização da abordagem territorial, na medida em que destacam reformas educacionais configuradas de acordo com as singularidades do campo e de suas territorialidades.

As políticas públicas do governo federal voltadas paraa E ducação do Campo são vinculadas à Secretaria de Educação Continuada, Alfabetização, Diversidade e Inclusão (SECADI), do Ministério da E ducação (MEC). E sse M inistério tem dialogado com o Ministério do Desenvolvimento Agrário (MDA) no sentido de construírem políticas públicas para os territórios do campo onde o processo educativo esteja em sintonia com as particularidades territoriais, colaborando, dessa forma, para um processo de desenvolvimento territorial mais sustentável.

Um exemplo significativo de política do governo federal para a Educação do Campo que pauta a abordagem territorial, fundamentada em diálogos entre 0 $M E C$ e os movimentos sociais, são as $D$ iretrizes $O$ peracionais para a $E$ ducação Básica nas E scolas do Campo, Resolução CNE / CEB N 1, de 3 de abril de 2002. 0 aspecto central que sustenta essas D iretrizes é o reconhecimento das diversas populações e de suas territorialidades que configuram os territórios do campo, como forma de contribuir para o desenvolvimento de ações políticas direcionadas a esses espaços singulares e, consequentemente, de contribuir para o desenvolvimento socioterritorial do país em sua totalidade.

N esse artigo, a dimensão territorial é analisada como indissociável da dimensão social, sendo esta entendida em todos os seus aspectos, inclusive 0 educacional. D essa forma, a diversidade socioterritorial do campo, na A mazônia Paraense (com suas inúmeras populações e suas territorialidades que, em muitas 
das vezes, se mesclam e confundem), deve ser problematizada na formulação e na efetivação de políticas educacionais para o território amazônico, sob pena de a educação e a escola se contraporem a essa diversidade socioterritorial e não colaborarem para o desenvolvimento de seus povos e territórios.

Em se tratando, especificamente, desses territórios do campo, são eles entendidos, neste artigo, como espaços que possuem dinâmicas naturais, produtivas, políticas, sociais e culturais próprias, profundamente ligadas às dinâmicas dos territórios urbanos, estabelecendo com eles relações dialéticas que conformam a totalidade social: "U m não pode ser entendido sem o outro, numa relação complementar, dialeticamente definida." (SAQUET, 2006, p. 160).

E m outras palavras, os territórios do campo se constituem no plano da unidade na diversidade; na relação entre o que há de universal na lógica capitalista e o que há de particular relacionado às características naturais, produtivas, sociais, políticas e culturais próprias de cada contexto socioterritorial, considerando que a própria singularidade desses territórios surge por meio da relação entreo universal e o particular (O LIVEIRA, 2010).

No caso do Brasil, os territórios do campo têm em comum o fato de serem espaços configurados por uma diversidade de populações, que convivem de forma complexa, histórica e dialeticamente, por meio de lutas e negociações, na conquista e na apropriação de seus territórios. E ssa diversidade de populações, cada qual com seus modos de vida, contribui para que cada território do campo, em meio aos aspectos gerais produzidos pela totalidade das relações capitalistas, possua singularidades que os diferencia um dos outros e dos territórios urbanos.

A A mazônia Paraense, lóusmais específico de nosso estudo, possui como característica marcante uma grande diversidade socioterritorial. E m relação aos seus territórios do campo, essa diversidade está, entre outros aspectos, essencialmente ligada à multiplicidade de populações que habitam esses territórios. As populações da Amazônia às quais nos referimos são as formadas por ribeirinhos, assentados, quilombolas, extrativistas, indígenas, agricultores familiares, colonos, entre outros. São populações que convivem por meio de uma teia complexa de relações sociais, culturais e territoriais. E ssa teia, podemos dizer que éformada pela conjugação de relações que são diversas e singulares aos territórios do campo com aquelas que são comuns à totalidade social.

Propõe-se que as políticas de E ducação do Campo, na A mazônia Paraense, estejam sintonizadas com a diversidade socioterritorial, com o objetivo de o próprio fenômeno educacional contribuir para o desenvolvimento moral, político e social de seus sujeitos. A verdadeira importância que a educação pode assumir está na sua intrínseca relação com a realidade socioterritorial concreta daqueles que pretende 
formar. Somente um processo educativo ligado a essa realidade pode ser formador de sujeitos conscientes e transformadores do mundo onde vivem.

\section{REFLEXÕESSOBRE TERRITÓRIO E TERRITORIALIDADE}

0 território é compreendido, neste artigo, como uma dimensão social, contrapondo-se à concepção tradicional advinda da geografia clássica que o concebe como um mero espaço-suporte de elementos naturais a ser utilizado e dominado por um E stado nacional soberano, no processo de seu desenvolvimento político-territorial.

A abordagem territorial possui sua importância para qualquer análise que se dedica à realidade social, na medida em que, como afirma Haesbaert,

[...] o próprio conceito de sociedade implica, de qualquer modo, sua espacialização ou, num sentido mais restrito, sua territorialização. Sociedade e espaço são dimensões gêmeas.

Não há como definir o indivíduo, o grupo, a comunidade, a sociedade sem ao mesmo tempo inseri-los num determinado contexto geográfico, territorial. (HAESBAERT, 2007, p. 20).

A discussão sobre a relação entre sociedade e território enseja, neste trabalho, um entendimento, ainda que inicial, sobre o processo de construção de territorialidades. Estas se apresentam, para Haesbaert (2007), como uma construção, por parte dos grupos sociais, de mediações espaciais (escola, igreja, plantação, indústria multinacional, etc.) queproporcionem o efetivo poder material esimbólico do território a esses grupos, poderes esses que são sempre multiescalares e multidimensionais, materiais e imateriais, de "dominação" e "apropriação" ao mesmo tempo. 0 caráter multiescalar do poder, do qual fala o autor, encontra-se na sua relação com o local, o regional e o global ea multidimensionalidade referese aos vários âmbitos do poder: econômico, político e, ou, cultural.

Ressaltamos que cada grupo social constrói sua relação com o território, usa seu território, territorializa-se integrando as dimensões ecológicas, econômicas, políticas e culturais de forma diferenciada, conforme sua identidade sociocultural e o tipo de relação que essa identidade assume com a natureza, em determinado momento histórico. Esse fato é um ponto essencial para as discussões sobre E ducação do Campo e políticas públicas na A mazônia.

Becker (2007), ao discutir sobre a geopolítica da Amazônia Brasileira, contribui para a compreensão da territorialidade enquanto fenômeno social cuja dinâmica está além da geopolítica do Estado. Ela afirma que

144

Ver a E ducação, v. 12, n. 1, p. 141-158, jan./ jun. 2011 
[...] a territorialidade, historicamente, é um valor da sociedade brasileira não somente por causa da geopolítica, mas porque nos próprios movimentos sociais perpassa a questão da territorialidade. Poderíamos indicar: Canudos, os quilombos, todos os movimentos de resistência revolucionária; os territórios indígenas, as reservas extrativistas. (BECKER, 2007, p. 29).

Gonçalves (2002, p.230) colabora para uma maior explicitação sobre a territorialidade, envolvendo a relação entre ela e o processo de territorialização. Para o autor, o processo de apropriação do espaço pelos grupos humanos, a territorialização, se diferencia de acordo com a diversidade ecológica, econômica, política e cultural existente no mundo. Como o mundo não é formado por um único conjunto ecológico, um único modelo econômico-político e por uma só cultura e como existem diferentes formas de relação entre esses aspectos, 0 processo de territorialização (apropriação) ocorre de maneira diversa, ensejando múltiplas territorialidades, que são expressões espaciais das múltiplas identidades existentes no planeta, com suas cargas materiais e simbólicas. As territorialidades são dinâmicas e mutáveis (e não universais e imutáveis), expressando, de acordo com cada circunstância, uma determinada identidade territorial.

O caráter do território concebido como uma dimensão social é problematizado, também, por Santos em seu ensaio "O retorno do território", no qual o autor afirma que "é o uso do território, e não o território em si que faz dele objeto de análise social" (SANTOS, 2002, p. 15), do que compreendemos que o que faz o território ser objeto de análise social é a maneira como ele está sendo utilizado pela sociedade, o que afirma a indissociabilidade entre território e sociedade.

Assim, não é o território enquanto base física que importa para uma teoria crítica de sociedade, mas a diferença, por exemplo, entre o uso do território pelo agronegócio e o seu uso pela agricultura familiar. Em outras palavras, o que é relevante, na realidade, é a análise do território enquanto uma construção dos diversos usos e intenções dos grupos, movimentos e classes sociais. E sse processo, no entanto, é dialético, pois a sociedade produz o território assim como o território é uma dimensão que influencia na formação de identidades sociais.

Colaborando para as discussões a respeito do caráter do território, Haesbaert (2007) desenvolve uma instigante discussão sobre a polissemia que o termo "território" possui, agrupando os significados de território em quatro vertentes: a política, a cultural, a econômica e a naturalista, cada uma enfatizando uma determinada dimensão do território, em detrimento das demais. 
A vertente política é relativa às relações espaço-poder e concebe o território como um espaço delimitado e controlado por um determinado poderio que, na maioria das vezes, relaciona-se ao domínio político do E stado nacional. A vertente cultural vê o território, sobretudo, como resultado da apropriação/ valorização simbólica, por determinado grupo, de seu espaço vivido. A vertente econômica concebe 0 território unicamente como fonte de recursos para o desenvolvimento das relações econômicas (como produto da divisão territorial do trabalho, por exemplo), relações essas inseridas no embate entre classes sociais e na relação capital-trabalho.

Por último, a vertente naturalista possui uma noção de território como espaço onde os homens se relacionam com o seu ambiente físico, procurando o equilíbrio entre as necessidades do grupo e os recursos físicos possibilitados pelo meio.

Em relação às perspectivas de território, Haesbaert (2007) as discute por meio de um debate que nos instiga a pensar sobre a perspectiva adotada no âmbito da E ducação do Campo. 0 autor destaca a existência de duas perspectivas, a parcial e a integradora/ relacional. A perspectiva parcial enfoca uma dimensão apenas do território (natural, econômica, política ou cultural), não dando conta de sua complexidade. A integradora/ relacional envolve, conjuntamente, todas as dimensões.

Para a perspectiva integradora/ relacional, o território carrega, de forma indissociável: "uma dimensão simbólica, ou cultural em sentido estrito, e uma dimensão material, de caráter predominantemente econômico-político", ambas em constante interação com a natureza. N esse sentido, o território é concebido como espaço formado pela integração/ relação entre as suas múltiplas dimensões, a econômica, a política, a cultural ea ecológica, apresentando-se por meio de uma concepção de espaço como um híbrido entre sociedade e natureza; entre política, cultura e economia; entre materialidade e idealidade (dimensão simbólica).

A perspectiva integradora/ relacional, com a qual concordamos, concebe o território enquanto dimensão da existência humana configurada por relações históricas imbricadas em manifestações de poder (HAESBAERT, 2007). Ela contribui para uma concepção de território na qual esteé constituído historicamente e na integração entre as dimensões material, simbólica e natural.

Tomando como base de nossas reflexões a perspectiva integradora/ relacional de território, observamos, no campo da A mazônia Paraense, a existência de inúmeras populações que, por meio de suas características materiais e simbólicas, constroem as suas várias territorialidades, provas indeléveis da diversidade socioterritorial que singulariza a A mazônia Paraense.

146

Ver a E ducação, v. 12, n. 1, p. 141-158, jan./ jun. 2011 
Os estudos de G onçalves (2005) sobre a A mazônia indicam que sua diversidade de populações protagoniza a complexidade da teia social-cultural existente em seus territórios do campo, complexidade esta que éum dos aspectos que possibilita a configuração das inúmeras territorialidades que presenciamos no espaço amazônico.

A partir das contribuições de Canen (2005), entendemos que a complexidade social-cultural pode ser traduzida em uma perspectiva de análise que problematiza a diversidade cultural existente entre os povos. Tal perspectiva busca romper com os preconceitos culturais e com os discursos que silenciam ou estereotipam determinadas culturas, sensibilizando para um reconhecimento das identidades culturais como sendo construções não homogêneas e absolutas, mas sempre diversas e relativas, dado o seu caráter histórico.

$\mathrm{N}$ a sessão seguinte, com o objetivo de dar materialidade a essa discussão, apresentamos a cartografia da diversidade socioterritorial do campo, na Amazònia Paraense.

\section{CARTOGRAFIA DA DIVERSIDADE SOCIOTERRITORIAL DO CAMPO NA AMAZÔNIA PARAENSE}

A cartografia apresentada nesse artigo explicita a diversidade socioterritorial do campo, na A mazônia Paraense, sendo formada pelo mapa geral das principais territorialidades amazônicas. Esse mapa pretende chamar a atenção para a diversidade socioterritorial da região e não somente para as áreas ocupadas pelos diversos grupos que vivem na Amazônia Paraense, na medida em que as territorialidades cartograf adas são concebidas como expressão daquela diversidade, ou seja, das inúmeras relações materiais e simbólicas existentes entre as populações e seus territórios. Essas territorialidades não são aspectos fixos, estáticos, mas expressões geográficas dinâmicas, construidas e re-construídas pelos sujeitos que se apropriam do território.

O mapa a seguir apresentado, produzido pelo Laboratório de G eoprocessamento, do N úcleo de M eio A mbiente da A mazônia, daU niversidade Federal do Pará, apresenta a cartografia das seguintes territorialidades na Amazônia Paraense: dos rios, das colônias rurais, dos assentamentos, das RE SE Xs (Reservas Extrativistas), dos quilombos e das áreas indígenas. 


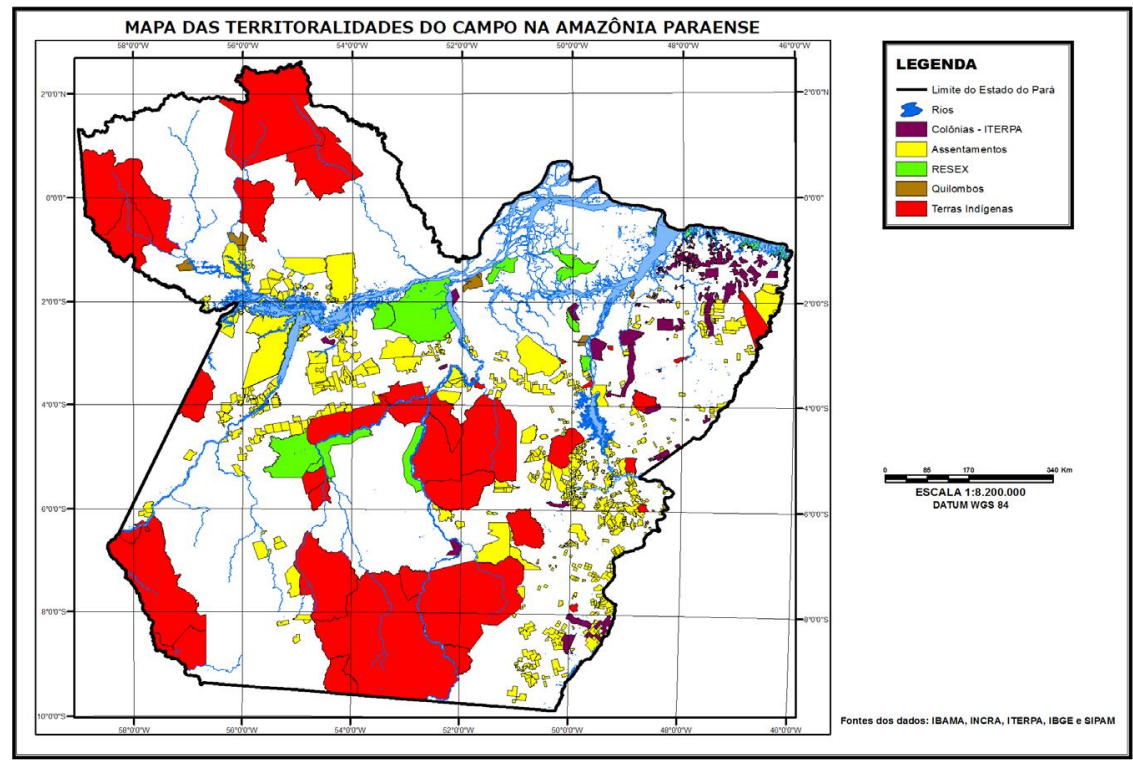

Figura 1. Territorialidades do campo na A mazônia Paraense

Fonte: Laboratório de G eoprocessamento - N UMA/UFPA - 2010

É importante destacar que a diversidade socioterritorial do campo, na A mazônia Paraense, não se resume a essas territorialidades acima cartografadas, na medida em que há comunidades praianas, que se concentram no litoral paraense, comunidades que vivem em fazendas, próximas às vicinais, em garimpos, que re-produzem sua existência de maneira própria a esses espaços geográficos particulares. No entanto, esclarecemos que as territorialidades apresentadas no mapa apresentado acima realizam as principais formas tradicionais de trabal ho e de reprodução da existência encontradas nos territórios do campo, na A mazônia Paraense, a saber: a agricultura no trabal ho com a terra, o extrativismo realizado na floresta, e a pesca nos rios, incluindo todas as suas expressões materiais e simbólicas.

As territorialidades do campo amazônicas, em termos da natureza do trabalho social, em muitos contextos geográficos se inter-relacionam, sendo extrativista o indígena e o quilombola e, ribeirinho, o colono e o extrativista, por exemplo. Isso faz com que as territorialidades não sejam rígidas e isoladas, mas dinâmicas e entrelaçadas (O LIVE IRA, 2010).

Torna-se necessário esclarecer que as territorialidades dos rios ou ribeirinhas, uma das mais significativas em se tratando de Amazônia, por se concentrar às margens dos rios, igarapés e furos, estão presentes em quase todo o território amazônico e confunde-se, em muitas das vezes, com as demais territorialidades cartografadas em nosso estudo.

148

Ver a E ducação, v. 12, n. 1, p. 141-158, jan./ jun. 2011 
As territorialidades das colônias rurais, cadastradas pelo Instituto $\mathrm{N}$ acional de Colonização e Reforma Agrária, abrangem uma área de 1.797.399ha e possuem como característica marcante a relação com 0 trabalho na agricultura de base familiar, encontrando-se concentradas nas regiões de integração do G uamá, do Rio Caeté e do Rio Capim e no N ordeste Paraense.

As territorialidades dos assentamentos ocupam uma área de 11.150.192ha, concentradas nas regiões de integração do Baixo A mazonas, Tapajós, X ingu, Lago de Tucuruí, de Carajás e do A raguaia. O s assentamentos referem-se aos territórios cadastrados pelo Instituto $\mathrm{N}$ acional de Reforma A grária, que são ocupados por famílias para a Reforma A grária, e, por meio do trabalho com a terra, de base familiar, traçam sua relação com o território.

As Reservas Extrativistas (RE SEXs) territorializam-se em um espaço de 4.429.296ha, concentrando-se nas regiões do Baixo Amazonas, do Xingu e de Marajó. Elas são territórios do poder público, onde vivem comunidades tradicionaisii que retiram sua subsistência da floresta.

Os quilombos configuram suas territorialidades em uma área de $586.479 \mathrm{ha}$, distribuída entre as regiões do Baixo Amazonas, de Marajó e do Tocantins. São territórios ocupados por comunidades negras tradicionais remanescentes dos quilombos originais, surgidos no Brasil na época da escravidão para servirem de locais de resistência.

A pesar de as territorialidades dos quilombos ocuparem a menor área entre as demais cartografadas, é no E stado do Pará que se concentra o maior número de territórios quilombolas titulados, colocando por terra teorias que defendem a fraca participação do negro na composição da sociedade amazônica paraense.

As territorialidades indigenas são as que ocupam a maior área, 28.514.634ha, o que pode ser explicado pela história secular de ocupação do território brasileiro por inúmeras sociedades indígenas e a sua luta pelo direito de propriedade do território. A área das territorialidades indígenas concentra-se nas regiões do Baixo A mazonas, Tapajós, Xingu e A raguaia.

A maioria dos povos indígenas, na A mazônia L egal, considerados, também, povos tradicionais, possuem um modo de vida vinculado diretamente às florestas $\mathrm{e}$ às águas. Em termos demográficos, a Amazônia Legal concentra, aproximadamente, 188 povos indígenas, o que corresponde a $77 \%$ do total nacional de 235 povos. $\mathrm{Na}$ Amazônia paraense, a população indígena distribui-se da seguinte forma: 25.962 índios, em territórios do campo, e 11.718, em territórios das cidades, perfazendo um total de 37.681 indigenas (CARVALHO; HECK; LOEBENS, 2005).

É importante ressaltar, ainda, que as territorialidades cartografadas nesse artigo convivem, em meio a relações de conflito e poder pela apropriação da terra, 
com territorialidades de outros grupos que também fazem parte da dinâmica territorial do campo na A mazônia paraense, a saber: latifundiários, madeireiros, fazendeiros, agroindustriais, etc. E sses grupos não foram explicitados, na presente discussão, pela delimitação do foco relacionado aos movimentos sociais populares do campo.

$\mathrm{N}$ a sessão seguinte, abordaremos a ação dos movimentos sociais populares do campo na definição de políticas públicas em Educação do Campo, considerando a diversidade socioterritorial, no Brasil e na A mazônia paraense.

POLÍTICAS PÚBLICAS E EDUCAÇÃO DO CAMPO: DESAFIOS QUANTO AO RECONI IECIMENTO DA DIVERSIDADE SOCIOTERRITORIAL

Os movimentos e organizações sociais populares do campo, nas últimas décadas, têm participado ativamente das disputas que envolvem a conquista da terra, o fortalecimento da produção de base familiar e a garantia do direito à vida com dignidade, constituindo-se enquanto sujeitos coletivos de direitos - entre os quais se encontra o direito à educação - e de produção de novas sociabilidades.

N essa caminhada de mobilização e protagonismo, a Artialação Naáonal Por umaE draçãodbCampotem assumido um papel destacado, para que não sejam reeditadas as tradicionais políticas de manutenção precária das escolas rurais, de cunho assistencialista, compensatório e compassivo, que reforçam 0 atraso e 0 abandono secular da educação dos povos que vivem daagricultura, do extrativismo e do trabalho do campo (CNEC, 2004).

E ssa articulação reúne movimentos e organizações sociais populares do campo, universidades, organizações da sociedade civil, órgãos do poder público e instituições internacionais, que compartilham princípios, valores e concepções político-pedagógicas, ese articulam para reivindicar políticas públicas de educação e desenvolvimento com qualidade social para as populações do campo, tais como: agricultores familiares, assentados, quilombolas, extrativistas, ribeirinhos e pescadores.

A primeira e a segunda edições Conferência N acional de E ducação do Campo, ocorridas em 1998 e 2004, em Luziânia (GO), constituíram-se em marcos históricos dessa articulação nacional, no processo de afirmar o direito das populações do campo à educação, ao reivindicar que a Educação do Campo fosse assumida como política pública; que os órgãos públicos responsáveis pela educação se fizessem mais presentes, reconhecendo a divida social, cultural e educativa que têm para com os sujeitos que vivem no campo e na floresta; e que fosse reconhecida a especificidade desses povos e de suas formas de viver e de ser, de formar-se,

150

Ver a E ducação, v. 12, n. 1, p. 141-158, jan./ jun. 2011 
socializar-se, aprender, de produzir e relacionar-se com o conhecimento, com as ciências e as tecnologias, com os valores e com a cultura. (CN E C, 2004).

$O$ utro indicativo desse processo organizativo em curso tem sido a pressão sobre as várias instâncias governamentais, para que renovem os processos de gestão da educação, ação que tem resultado num esforço de determinadas Secretarias de Educação para se tornarem mais sensiveis à inclusão da Educação do Campo em sua agenda política, criando espaços esituações em que as singularidades do campo sejam reconhecidas e valorizadas. N essa perspectiva, o próprio ME C respondeu a essa mobilização, com a criação, em 2004, da Secretaria de E ducação Continuada, A lfabetização e D iversidade (SE CAD ), na qual se insere a Coordenação G eral da E ducação do Campo, que assumiu o compromisso de efetivar uma política de educação que respeite a diversidade cultural e as diferentes experiências de educação em desenvolvimento, em todas as regiões do país, ampliando a oferta de educação básica nas escolas do campo. (SE CAD, 2005).

Nos documentos que expressam as intencionalidades oficiais quanto à definição e implementação de políticas educacionais, têm-se reconhecida a reivindicação dos movimentos sociais de conceber e valorizar o campo, com suas diversas territorialidades, englobando os espaços da floresta, da pecuária, das minas, da agricultura, dos pescadores, dos caiçaras, dos ribeirinhos e dos extrativistas, como espaço de inclusão e desenvolvimento com sustentabilidade. (SE CAD, 2005).

E ntre os acontecimentos que marcaram a mobilização por uma E ducação do Campo, no país, o Ministério da Educação institucionalizou, em 2007, a Comissão $\mathrm{N}$ acional de Educação do Campo (CONEC), formada por representantes dos demais setores do M inistério, FNDE, INEP, MDA, UNDIME e CONSEP, das organizações e movimentos sociais do campo, para assessorar a Coordenação G eral de E ducação do Campo na formulação e na implementação dos programas e ações de E ducação do Campo. 0 s movimentos sociais e sindicais do campo, em agosto de 2010, decidiram criar o Fórum N acional de E ducação do Campo, com autonomia para debater com o poder público sobre as proposições voltadas para implantação, fortalecimento e consolidação de políticas públicas de educação, a partir da diversidade de questões que envolvem a $\mathrm{E}$ ducação do Campo.

O Fórum por uma E ducação do Campo intenciona garantir que as políticas públicas a serem efetivadas sejam estratégicas para a construção de um projeto contra-hegemônico de campo, ao contribuir para a melhoria da educação no meio rural e para a superação do processo de desigualdade educacional a que estão submetidas, historicamente, suas populações, refletido nos dados educacionais e de políticas públicas inadequadas ou ausentes (FN E C, 2010). 
Conquistas importantes referem-se, ainda, à definição de marcos regulatórios das políticas de E ducação do Campo, envolvendo a participação dos M ovimentos Sociais. Podemos apresentar como marcos regulatórios: as $D$ iretrizes 0 peracionais para a E ducação Básica nas E scolas do Campo (Resolução no 1/ 2002, do CNE/ CE B); as D iretrizes Complementares para o D esenvolvimento dePolíticas Públicas de A tendimento da E ducação Básica do Campo (Resolução nํ2/ 2008, do CN E / CEB); o Reconhecimento dos Dias Letivos para a aplicação da Pedagogia da Alternância nos Centros Familiares de Formação por Alternância (Parecer no 1/2006, do CNE/CEB); e o Decreto, assinado pelo presidente Lula, estabelecendo referências sobre a política de E ducação do Campo e regulamenta o Programa N acional de E ducação na Reforma A grária - PRO N E RA (BRASIL, 2010).

Todas essas legislações compreendem as populações do campo a partir de sua diversidade socioterritorial e de sua constituição por agricultores familiares, extrativistas, pescado res artesanais, ribeirinhos, assentados e acampados da reforma agrária, trabalhadores rurais assalariados, quilombolas, caiçaras, povos da floresta, caboclos; e estabelecem que a escola deve atender a esses cidadãos respeitando a diversidade, nos aspectos sociais, culturais, territoriais, políticos, econômicos, de gênero, raça e etnia.

N a Amazônia Paraense, articulando-se a essa mesma dinâmica, os movimentos sociais representativos das populações do campo, entre eles 0 Maimeto dos Trabalhadores Rurais SenTera (MST), a Feeleração dos Trabalhadores da A gicultura (FETA GRI), a A ssaiaçãoRejiand das Casas Familiares Rurais db Pará (ARCAFA R/ PA), oMairento dos Ribérinhos eV árzessda A bateduba (MORIVA), vêm demarcando o seu espaço de militância de forma singular, com impacto na sua estrutura agrária e no questionamento do uso do território e dos recursos naturais de forma predatória, reivindicando um novo jeito de olhar e produzir a existência, a cultura e a relação com a natureza.

Esses mesmos sujeitos coletivos ajudam a entrelaçar e fortalecer os fios da rede que vem sendo formada através do Moimento Paraensepor uma Educação do Campa que tem no FớumParånedeE ducacão do Campo sua expressão mais significativa de organização e mobilização pela construção de um projeto popular de desenvolvimento e de educação. OFóumParaenedeE ducaçãodo Campo aglutina movimentos sociais, entidades da sociedade civil, universidades e instituições governamentais da sociedade paraense que, compartilhando princípios, buscam implementar, apoiar e fortalecer políticas públicas, estratégias e experiências de E ducação do Campo e desenvolvimento rural com qualidade socioambiental para todos os cidadãos paraenses, sobretudo para as populações do campo (FPE CD R, 2007).

152

Ver a E ducação, v. 12, n. 1, p. 141-158, jan./ jun. 2011 
Entre os marcos importantes da caminhada do Fórum são destaques as edições I, II, III e IV do Seminário Estadual de Educação do Campo, I e II do Seminário E stadual de Juventude do Campo, realizados entre 2004 a 2010, assim como o I e o II E ncontros de Pesquisa em E ducação do Campo do E stado do Pará, realizados em 2008 e 2010, na A mazônia paraense.

Esses eventos têm mobilizado um número cada vez mais abrangente de sujeitos, instituições públicas, movimentos sociais e entidades não governamentais nos processos de definição e implementação de políticas e práticas educacionais sintonizadas com a realidade do campo, constituindo-se em espaços onde se manifestam, em depoimentos, as insatisfações, aspirações e reivindicações com relação à educação que se deseja sejam concretizadas nas escolas do campo.

O trecho do Manifesto do III Seminário Estadual de Educação e do I Seminário E stadual de Juventude do Campo, da F loresta e das Á guas da A mazônia Paraense, realizados entre os dias 13 e 17 de junho de 2007, é ilustrativo da significância desses eventos:

Somos homens e mulheres do campo, das águas e da floresta da A mazônia Paraense (agricultores/ as, assentados/ as, ribeirinhos/ as, pescadores/ as, seringueiros, indígenas, quilombolas), educadores/ as e gestores/ as das Redes Estadual e Municipais de Ensino, de Escolas Públicas, Movimentos Sociais e Centros Familiares de Formação por Alternância (CEFFA's - CFR e EFA); E ducandos do PRO N ERA, do Programa Saberes da Terra e do Programa Jovem Saber, D ocentes-pesquisadores e estudantes (graduação e pós-graduação) de U niversidades Públicas; representantes de M ovimentos Sociais, Sindicais e Comunitários; Instituições de Pesquisa, Entidades da Sociedade Civil, D irigentes de Secretarias Municipais e E stadual de E ducação, de Associações de Municípios, do Ministério da E ducação, M inistério do D esenvolvimento A grário, I NCRA, de órgãos de desenvolvimento rural (E MATER, SAG RI) e outros órgãos de gestão pública com atuação na educação e no desenvolvimento do campo

Somos sujeitos que lutam e enfrentam desafios nesse Estado da A mazônia brasileira, comprometidos com a ruptura da lógica perversa de exploração e expropriação das riquezas naturais, sociais e cultural da região, que historicamente têm atendido aos interesses de grupos econômicos minoritários e gerado beneficios alheios às necessidades e aspirações das populações amazônicas. 
Somos sujeitos que tem desencadeado múltiplos processos reivindicatórios pela garantia dos direitos humanos, convictos de que o acesso à terra, trabalho, justiça, saúde, educação, água, crédito diferenciado, estrada, luz, preservação ambiental, entre outros bens, édeterminante para a qualidade de vida e dignidade dos sujeitos do campo. As Marchas, os $G$ ritos da Terra, as ocupações de terra e de estradas, as manifestações populares são evidências inequívocas do vigor da luta dos movimentos sociais.

Somos sujeitos que lutam por um projeto de nação e de desenvolvimento do campo comprometidos com a sustentabilidade presente e de gerações futuras, em que a justiça ambiental hegemonize e que os modos de existir e produzir dos camponeses sejam imperativos desse projeto. Lutamos por um campo que seja espaço de produção econômica e sociocultural, em que suas populações vivam com dignidade e tenham na cidade um espaço de interação, mas não de dependência ou subordinação. "L utamos por um novo projeto de desenvolvimento rural referenciado no enfoque sustentado e territorial" (FPEDC, 2007).

E sse esforço coletivo tem impactado no reconhecimento da E ducação do Campo enquanto política pública e se materializado na efetivação de programas e ações que viabilizam a garantia do direito à educação com o protagonismo das populações e sujeitos que vivem no campo. Como exemplo, o Programa Projovem

Campo destina-se a agricultores de 18 a 29 anos que não tenham concluído o ensino fundamental, utilizando a formação em regime de alternància para certificá-los no ensino fundamental, com qualificação em agricultura familiar; o PROCAMPO - Programa de Apoio à Formação Superior em Licenciatura em Educação no Campo - oferece graduação a professores das escolas rurais que lecionam nos anos finais do ensino fundamental e no ensino médio; o Programa Escola Ativa responsabiliza-se pela formação dos gestores e professores que atuam nas escolas rurais multisseriadas, as quais atendem, em uma mesma sala de aula, estudantes dos anos iniciais do ensino fundamental; e o Programa $\mathrm{N}$ acional de E ducação na Reforma A grária, que oferece educação escolar aos jovens e adultos das famílias beneficiárias dos projetos de assentamento criados ou reconhecidos pelo INCRA, em todos os níveis de ensino.

Esses programas têm sido desenvolvidos, na A mazônia Paraense, por meio da aproximação entre os órgãos públicos federais, estaduais e municipais, as universidades e as organizações e movimentos sociais populares do campo,

154

Ver a E ducação, v. 12, n. 1, p. 141-158, jan./ jun. 2011 
assumindo o desafio de pautar as questões referentes a uma abordagem territorial nas políticas públicas que chegam até as escolas do campo.

E sse fato fundamenta-se no reconhecimento de que aE ducação do Campo deve ser pensada e colocada em prática possuindo um vínculo estreito com as singularidades próprias dos ter ritórios aos quais se destina, mas sem fragmentação, ou seja, percebendo o território amazônico em relação com os demais territórios do B rasil e do mundo, e analisando seus aspectos ecológicos, econômicos, políticos e culturais de forma relacional (FERNANDES, 1999).

Contudo, o desafio que se apresenta às populações do campo da Amazônia paraense continua sendo o alcance da função da E ducação do Campo, enquanto colaboradora da sustentabilidade ecológica em associação com o fortalecimento da cultura e das relações sociais próprias dos territórios e das territorialidades do campo.

Trata-se de fazer com quea E ducação do Campo eas políticas educacionais a ela vinculadas, na Amazônia paraense, tomem em conta que há várias "amazônias" na A mazônia, muitas delas contraditórias entre si, e que há que se optar por aquelas que tornem possível uma vida melhor não só para seus habitantes, mas também para o planeta. E sse caminho passa, necessariamente, por incorporar suas populações aos direitos básicos de cidadania, oferecendo-Ihes condições de fazer melhor o que já sabem, além de buscar novos caminhos a partir da experiência acumulada (G O N ÇALVES, 2005). Exige-se, assim, uma visão complexa e relacional do território, que não dissocie ecologia de justiça social e cidadania.

\section{NOTAS}

'Para fins de planejamento estadual, o território paraense está dividido em doze regiões de integração: A raguaia, Baixo A mazonas, Carajás, G uamá, Lago Tucuruí, M arajó, M etropolitana, Rio Caeté, Rio Capim, Tapajós, Tocantis e X ingu.

"O termo "tradicionais", de acordo com Linhares (2010), é usado para definir grupos humanos diferenciados so b o ponto devista sociocultural, que reproduzem, historicamente, seu modo de vida com base na cooperação social e em relações próprias com a natureza. Essa noção refere-se, por exemplo, tanto às comunidades extrativistas quilombolas quanto aos povos indígenas, que desenvolveram modos particulares de existência na relação com os seus territórios. 


\section{REFERENCIAS}

BECKER, Bertha. A Amazônia e a política ambiental brasileira. In: SANTOS, M ilton; BECKER, Bertha (O rg.). Território, territórios: ensaios sobre o ordenamento territorial. Rio de Janeiro: Lamparina, 2007.

BRASIL. Decreto $N^{\circ} 7.352$, de 4 de novembro de 2010. Dispõe sobre a política de E ducação do Campo e o Programa N acional de E ducação na Reforma A grária - PRONERA. Diário Oficial da União. Brasília, 5 nov. 2010. Disponível em: $<$ http://www.planalto.gov.br/ccivil_03/_Ato2007-2010/2010/Decreto/D7352. htm>. A cesso em: 02 abr. 2010.

BRA SI L. M inistério da E ducação (ME C). Conselho N acional deE ducação (CN E ). Resolução CNE / CEB N o 1, de 3 de abril de 2002. Institui D iretrizes 0 peracionais para a Educação Básica nas Escolas do campo. Diário Oficial da União. Brasília (DF), 09 abr. 2002, p. 32, Seç.1. Disponivel em: <http://portal.mec.gov.br/cne/ arquivos/ pdf/ CE B012002.pdf>. A cesso em: 30 abr. 2010.

E stabelece diretrizes complementares, normas e princípios para o desenvolvimento de políticas públicas de atendimento da Educação Básica do Campo. Diário Oficial da União. Brasilia (DF), 29 abr. 2008, p. 25-26, Seç.1. Disponivel em: <http:// portal.mec.gov.br/ cne/ arquivos/ pdf/2008/ rceb002_08.pdf>. A cesso em: 30 abr. 2010

Parecer CNE/CEB No 1/2006. Dias Letivos para a aplicação da Pedagogia da A Iternância nos Centros Familiares de Formação por Alternância. Parecer homologado por despacho do M inistro, publicado no D iário Oficial da União - Brasilia/DF, de 15 de março de 2006. Disponível em: <http:// portal.mec.gov.br/cne/arquivos/pdf/pceb001_06.pdf>. Acesso em:01 fev. 2010.

BRASIL. Ministério da E ducação (MEC). Secretaria de E ducação Continuada, Alfabetização e Diversidade (SECAD). E lementos para um Plano $\mathrm{N}$ acional de E ducação do Campo: por uma política de E ducação do Campo. D isponível em: http:// portal.mec.gov.br/ secad/ . A cesso em: 20/ 10/ 2005.

CANEN, Ana. Sentidos e dilemas do multiculturalismo: desafios curriculares para o novo milênio. I n: LO PE S; A liceCasimiro; M ACE D 0, E lizabeth Macedo (O rg.). Currículo: debates contemporâneos. São Paulo: Cortez, 2005.

CARVALHO, Priscila D.; HECK, Egon; LOEBENS, Francisco Loebens. Amazônia indígena: conquista e desafios. Estudos Avançados, São Paulo, v. 19,

156

Ver a E ducação, v. 12, n. 1, p. 141-158, jan./ jun. 2011 
n. 53, p. 237-255, jan./abr.2005. (Dossiê Amazônia brasileira I). Disponivel em: $<$ http://www.scielo.br/pdf/ea/v19n53/24091.pdf> Acessado em: 03/08/2010.

CON FERÊ N CIA N ACIO N AL POR UMA EDUCAÇÃO DO CAMPO (CNEC). Por uma Política Pública de Educação do Campo. Texto Base. Conferência N acional por uma E ducação do Campo, 2. Luziânia (G O ): CN E C, 2004.

FE RN AN DE S, Bernardes M ançano. Por umaE ducação do Campo. In: A RROYO, Miguel G onzalez. A educação básica e o movimento social do campo. B raślial DF: Articulação Por uma Educação do Campo, 1999. (Coleção Por uma Educação do Campo, v. 2).

FÓRUM PARAENSE DE EDUCAÇÃO DO CAMPO (FPEC). Seminário Estadual de Educação, 3; Seminário Estadual de Juventude do Campo, da Floresta e das Águas da Amazônia Paraense, 1. 2007. Ananindeu (PA), Manifesto. (digitalizado). Ananindeua (PA): FPEC, 2007.

FÓRUM NACIONAL DE EDUCAÇÃO DO CAMPO (FONEC). Carta de Criação do FO N E C. Brasília, agosto de 2010. (digitalizado).

G O N ÇA LVE S, Carlos Walter Porto. A mazônia, A mazônias. São Paulo: Contexto, 2005.

. Das geografias as geo-grafias: um mundo em busca de novas territorialidades. In: CE CE N A, A na E sther; SADER, E mir (Comps.). La guerra infinita. Hegemonía y terror mundial. Buenos Aires (AR): CLACSO, 2002, p.217256. Disponivel em: <http://www. bibliotecavirtual.clacso.org.ar/ar/libros/ cecena/porto.pdf>. Acessado em: 03/03/2009.

HAESBAERT, Rogério. O mito da desterritorialização: do fim dos territórios à multiterritorialidade. 3. ed. Rio de Janeiro: Bertrand Brasil, 2007.

LINHARES, Jairo Fernando Pereira. Populações tradicionais da Amazônia e territórios de biodiversidade. D isponível em: <http:/ / www.ppgcsoc.ufma. $\mathrm{br} /$ index.php?option $=\mathrm{com} \_$content\&view $=$article\&id $=311 \&$ catid $=72 \&$ item id=114>. A cessado em: 02/ 10/ 2010.

O LIVEIRA, Lorena M aria M ourão. E ducação do Campo ecurrículo na A mazônia Paraense: o enfoque dado à diversidade sócio-territorial nas diretrizes curriculares da SEDUC/PA. 2010. 100f. Dissertação (Mestrado em Educação)-Universidade Federal do Pará, Instituto de Ciências da E ducação. B elém (PA), 2010. 
SAN TOS, Milton. 0 retorno do território. In: SANTO S, Milton; SO UZA, M aria A délia A. de (0 rg.). Território, globalização e fragmentação. 5. ed. São Paulo: Hucitec, 2002.

SAQUET, Marcos Aurélio. Por uma abordagem territorial das relações urbanorurais no Sudeste paranaense. In: SPO SETO, M aria E ncarnação Beltrão; WHITACKER, Arthur Magon (Org). Cidade e Campo: relações e contradições entre urbano e rural. São Paulo: Expressão Popular, 2006. 